\title{
What Toxicity May Result from the Xenobiotic Responsible for the Finding on This Plain Film? Answer: Reduced Iron, Found in Heating Pads and Instant Hand Warmers, May Result in Elevated Serum Iron Concentrations and Subsequent Iron Toxicity
}

\author{
Jon B. Cole $\cdot$ Samuel J. Stellpflug $\cdot$ Christian P. Lintner
}

Published online: 5 August 2011

(C) American College of Medical Toxicology 2011

\begin{abstract}
Disposable heating pads are commonly used products, with reduced iron as their active ingredient. Reduced iron is not expected to cause significant toxicity when ingested orally. We report a case of accidental heating pad ingestion seen on abdominal plain films that resulted in significantly elevated serum iron concentrations.
\end{abstract}

Keywords Iron $\cdot$ Reduced iron $\cdot$ Hand warmer $\cdot$ X-ray

\section{Background}

Instant hand warmers and disposable heating pads are commonly used over-the-counter products. Their active ingredient is reduced iron-an amorphous powder without crystals prepared by reduction of iron oxide by hydrogen [1]. Reduced iron oxidizes when exposed to oxygen; this exothermic reaction produces the desired heating effect [2]. Classic teaching is that reduced iron is not expected to cause significant toxicity when ingested orally $[1,3]$. This supposition, however, is based on a very limited number of human cases [2]. We report a case of accidental heating pad ingestion visible on abdominal plain films that resulted in significantly elevated serum iron levels.

Previous Presentation This project was previously presented at the 2010 North American Congress of Clinical Toxicology as a Poster Presentation in Denver, CO, USA. The abstract was published in Clinical Toxicology.

J. B. Cole $(\bowtie) \cdot$ S. J. Stellpflug $\cdot$ C. P. Lintner

Hennepin Regional Poison Center,

701 Park Avenue,

Minneapolis, MN 55415, USA

e-mail: jonbcole@gmail.com

\section{Case Report}

A 52-year-old man opened a Heat Treat ${ }^{\circledR}$ disposable heating pad, thinking it was instant coffee, placed the contents into a cup, added water, and drank it. After realizing his mistake, the patient was referred to an emergency department by poison control. A serum iron concentration 3-h post-ingestion was $308 \mathrm{mcg} / \mathrm{dL}$ (normal range 40-150). Coincidentally, the patient had an iron level 1 week prior of $142 \mathrm{mcg} / \mathrm{dL}$ in a work-up for chronic mild pancytopenia. Plain films revealed high-density material within the stomach (Fig. 1). Whole bowel irrigation was performed using $4 \mathrm{~L}$ /day of polyethylene glycol electrolyte lavage solution for 2 days, resulting in frequent liquid stools. The patient had a history of chronic abdominal pain, and reported it was worse than baseline. He also complained of nausea but did not vomit. His serum iron concentration peaked at $373 \mathrm{mcg} / \mathrm{dL} 7 \mathrm{~h}$ post-ingestion. Two days post-ingestion, the iron concentration was still elevated at $280 \mathrm{mcg} / \mathrm{dL}$ but fell to $91 \mathrm{mcg} / \mathrm{dL}$ the next day. The patient's abdominal pain returned to baseline 2 days post-ingestion, and the remainder of his symptoms resolved. A repeat plain film revealed resolution of the acute finding (Fig. 2). The patient was discharged on hospital day 3 with no sequelae.

\section{Discussion}

Reduced iron has been reported to cause little to minimal effects [1-3].There have been reports of accidental ingestions of reduced iron with minimal elevations of serum iron; however, the elevated levels all returned to normal 


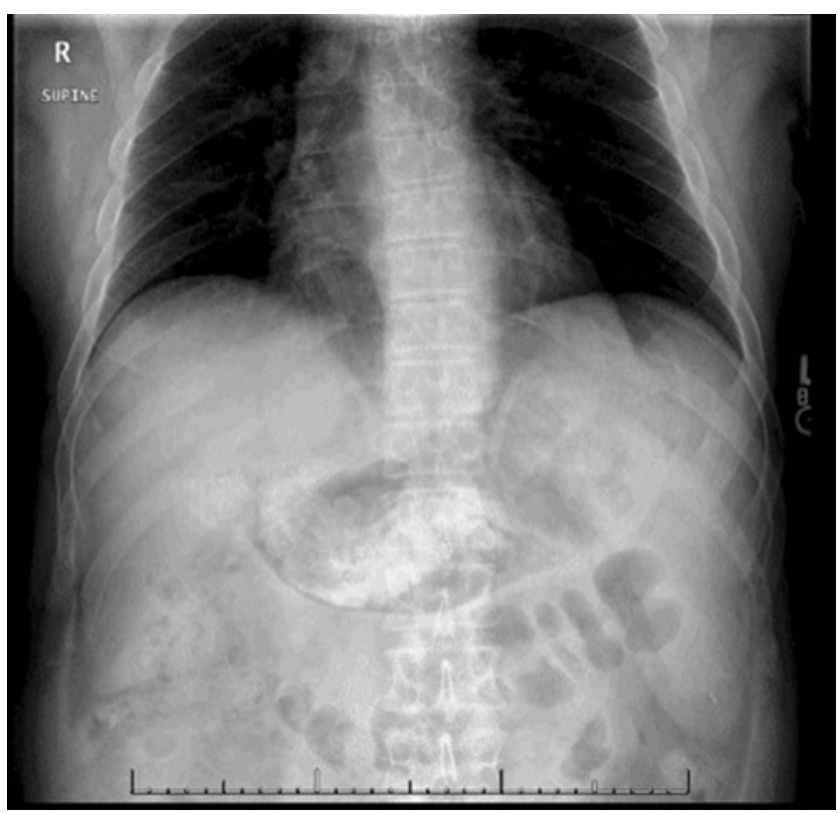

Fig. 1 Plain films revealed high-density material within the stomach

range within the first $24 \mathrm{~h}$ [2]. The authors in this series noted a theoretical risk of iron poisoning; mechanistically, this is possible as the iron oxides may react with hydrochloric acid in the stomach to produce the more easily absorbed iron chloride [4]. Our case demonstrates it is possible to cause significant elevation of serum iron levels from accidental reduced iron ingestions.

\section{Conclusion}

Instant hand warmers and disposable heating pads, when ingested, can result in toxic iron concentrations. Poison center personnel, medical toxicologists, and other providers who care for poisoned patients should be aware of this effect. Patients ingesting reduced iron should be monitored

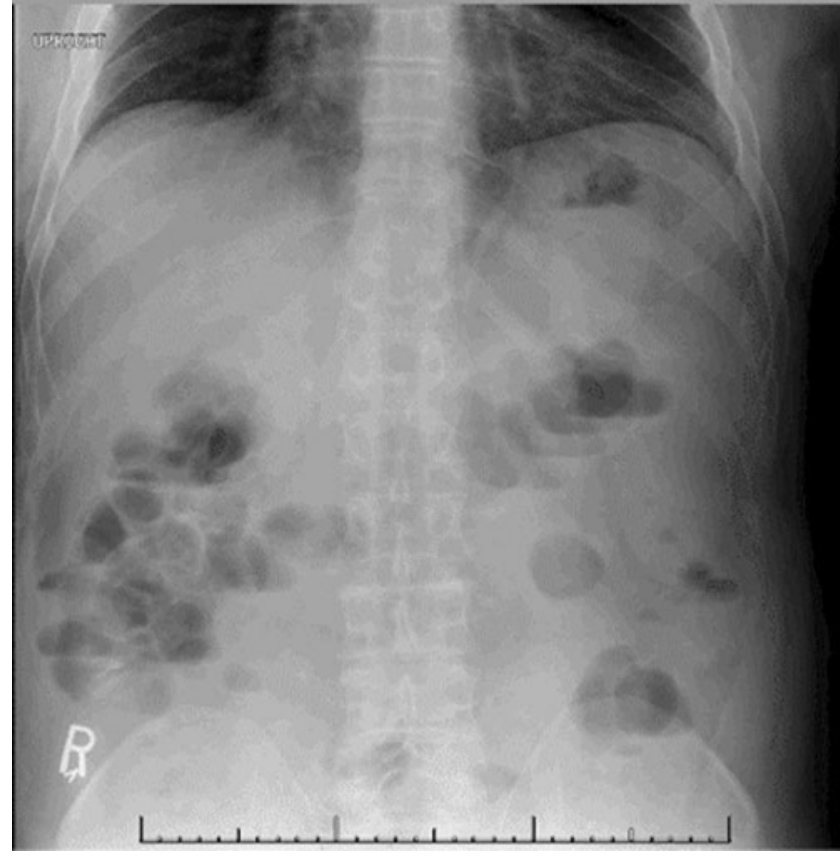

Fig. 2 A repeat plain film revealed resolution of the acute finding

until symptoms resolve and serum iron concentrations are normal or trending downward.

Conflicts of Interest None of the authors have any financial or academic conflicts to report.

\section{References}

1. Boyd EM, Shanas MN (1963) The acute oral toxicity of reduced iron. Can Med Ass J 89:171-175

2. Tam AYB, Chan YC, Lau FL (2008) A case series of accidental ingestion of hand warmer. Clin Toxicol 46:900-904

3. Boyd EM, Shanas MN (1967) Studies on the low toxicity of reduced iron. Can Med Ass J 96:1141-1146

4. Tenenbein M (1998) Toxicokinetics and toxicodynamics of iron poisoning. Toxicol Lett 102-103:653-656 